\title{
Growth performance, haemo-biochemical parameters and meat quality characteristics of male Japanese quails fed a Lippia javanica-based diet
}

\author{
C.M. Mnisi ${ }^{\#, 1,2}$, T.B. Matshogo ${ }^{1,2}$, R. van Niekerk ${ }^{1,2} \&$ V. Mlambo ${ }^{1,2}$ \\ ${ }^{1}$ Department of Animal Science, Faculty of Agriculture, Science and Technology, North-West University, P Bag \\ x2046, Mmabatho 2735, Mafikeng, South Africa \\ ${ }^{2}$ Food Security and Safety Niche area, Faculty of Agriculture, Science and Technology, North West University, \\ P Bag x2046, Mmabatho, 2735, South Africa
}

(Received 6 June 2017; Accepted 11 August 2017; First published online 4 September 2017)

Copyright resides with the authors in terms of the Creative Commons Attribution 4.0 South African License.
See: http://creativecommons.org/licenses/by/4.0/za
Condition of use: The user may copy, distribute, transmit and adapt the work, but must recognize the authors and the South African
Journal of Animal Science.

\begin{abstract}
A total of 105 male Japanese quails $(153.2 \pm 10.21 \mathrm{~g})$ (Cortunix cortunix japonica) were reared in an environmentally controlled house to investigate the effect of inclusion of Lippia javanica leaf meal on growth performance, haematological and serum biochemical parameters, and carcass and meat quality characteristics. The quails were randomly allocated to 15 pens, with each pen holding 7 quails. Pens were then randomly allocated to the following experimental diets: 1) commercial grower diet without antibiotics [NegCon]; 2) commercial grower diet with antibiotics, coxistac and olaquindox [PosCon]; and 3) commercial grower diet without antibiotics in which L. javanica was included at the rate of $25 \mathrm{~g} / \mathrm{kg}$ [Ljav25]. Experimental diets and fresh water were offered ad libitum. Weekly feed intake and body weights were recorded to calculate feed conversion efficiency (FCE). At 9 weeks of age, quails were slaughtered at a local poultry abattoir for assessment of blood parameters, carcass and meat quality characteristics. Repeated measures analysis showed no significant week $\times$ diet interaction effect on average weekly feed intake (AWFI), average weekly weight gain (AWG) and FCE. Diet had no significant influence on AWFI, AWG, FCE, and haematological parameters. There was no dietary effect on overall FI, overall WG and overall FCE. Alanine transaminase (ALT) was the only serum biochemical parameter influenced by diet. Quails offered Ljav25 had higher ALT content $(56.83 \mathrm{u} / \mathrm{L})$ than those offered PosCon $(18.0 \mathrm{u} / \mathrm{L})$. Diets had no significant impact on carcass characteristics and internal organs, except for gizzard weights. Immediately after slaughter, diets caused no effect on meat quality parameters, except meat lightness $\left(L^{*}\right)$, whereas at $24 \mathrm{~h}$ post slaughter, diets had significant impact on meat yellowness $\left(b^{*}\right)$. No dietary variation was observed for peak positive force (PPF) values of quail meat. NegCon diet promoted the least cooking losses (16.51\%) when compared to PosCon and Ljav25 diets, which significantly did not differ. It was concluded that inclusion of $L$. javanica in quail diets at $25 \mathrm{~g} / \mathrm{kg}$ feed promoted similar growth performance, health status, and carcass and meat quality traits as the commercial grower diet containing antibiotics. Lippia javanica leaf meal, therefore, has potential as an alternative to antibiotic growth promoters in Japanese quails.
\end{abstract}

Keywords: Antibiotics, health, Lippia javanica, physiological response, quails

\# Corresponding author: mnisiecm@gmail.com

\section{Introduction}

Japanese quails (Coturnix coturnix japonica) have recently emerged as new entrants into the poultry industry in many countries around the world (Ayaşan, 2013; Khosravi et al., 2016). Recently, quails have been shown to have several attributes such as resistance to disease, tolerance to harsh environmental conditions, early sexual maturity and fast growth rates (Sarıçiçek et al., 2005; Ayaşan et al., 2011; Khosravi et al., 2016; Cong et al., 2017). These attributes make the quail a suitable bird species for intensive food production. This has prompted intense efforts to improve their production and thus ensure sufficient nutrition for a fast-growing human population. In order to ensure that quails receive adequate nutrition, they are mostly reared in intensive production systems to enable the birds to express their full genetic potential for growth and performance. The drawback of intensive production system include high feed (and other inputs) costs as well as possible outbreaks of diseases. Faced with these two challenges, quail farmers may resort to the use of antibiotic growth promoters (AGPs) (Landy et al., 2011). The use of feed additives, specifically AGPs, has largely been proven to promote feed utilisation, gut health, and to improve weight gain and 
conversion of feed into body mass (Dibner \& Richards, 2005). Wallace et al. (2010) also reported that inclusion of AGPs in poultry diets controls intestinal pathogens and increases weight gain. However, their continued use has attracted unprecedented resistance from consumers and other stakeholders, leading to bans being enforced in several countries (Aarestrup, 2003). Unfortunately, AGPs not only contribute to high cost of production in the poultry industry but also induce strong public concerns of antibiotic residues in meat. The use of commercial AGPs has also been implicated in the development of pathogenic bacterial resistance (Phillips et al., 2004; Toghyani et al., 2010), which have resulted in their ban in Sweden in 1986 and the European Union in 1997 (Aarestrup, 2003; Kocher \& Choct, 2008). Phytogenic feed additives have recently gained interest for use as alternatives in poultry diets (Windisch et al., 2008). There is, therefore, a dire need to identify and evaluate plant-based alternatives to antibiotic growth promoters that can be utilized to enhance growth performance and the quality of meat in Japanese quails.

One such possible alternative is Lippia javanica, an indigenous plant with potential health benefits, in addition to being a source of nutrients. According to Windisch et al. (2008), essential oils and phenolic compounds tend to be the active ingredients of medicinal plants. Indeed, there is evidence that $L$. javanica has been used as an ethno-veterinary drug to treat a wide array of livestock infections in communal areas (Muyima et al., 2004). Viljoen et al. (2015) reported that the essential oils of the aerial parts of Lippia have antimicrobial activity against Klebsiella pneumoniae, Bacillus cereus and Cryptococcus neoformans. Fever tea, as it is commonly known, contains secondary plant metabolites such as terpenoids, essential oils, alkaloids, lectins and polypeptides that have been shown to possess analgesic, anti-inflammatory and antipyretic activities (Abena et al., 2003). These compounds have been shown to inhibit Escherichia coli, Bacillus subtilis and Staphylococcus aureus (Manezhe et al., 2004). A few studies have attempted to use $L$. javanica as a natural antibiotic that can be used as an alternative to commercial antibiotic growth promoters (Toghyani et al., 2010; Mpofu et al., 2016) but no such reports exist in Japanese quails. In other studies, Lippia javanica has been reported to positively impact meat quality, in general, and unsaturated fatty acids composition of meat, in particular (Sreelatha \& Padma, 2009; Qwele et al., 2013; Mpofu et al., 2016). It is, therefore, important to evaluate $L$. javanica as an alternative to AGP in Japanese quails diets in order to reduce dependency on AGPs and thus ensure sustainable food and nutrition security and safety for the growing human population. This study was, thus, designed to investigate the effect of including $L$. javanica leaf meal as a dietary additive, on growth performance, haemo-biochemical parameters, carcass characteristics and meat quality attributes of male Japanese quails. The study tested the null hypothesis that supplementation with $L$. javanica leaf meal does not affect growth performance, haemo-biochemical parameters, carcass characteristics, and meat quality in male Japanese quails.

\section{Materials and methods}

Lippia javanica was hand-harvested at Mafikeng game reserve located in the semi-arid region of the North-West province, South Africa ( $\left.25^{\circ} 84^{\prime} 00^{\prime \prime} \mathrm{S}, 2^{\circ} 62^{\prime} 33^{\prime \prime} \mathrm{E}\right)$. The game reserve is $1762 \mathrm{~m}$ above sea level with annual rainfall ranging from $300-600 \mathrm{~mm}$; in general the most rain fall is likely to occur during summer between November and March. The temperatures around the area range from $3-37^{\circ} \mathrm{C}$. The soil type differs across the game reserve from red sandy to clay.

Harvesting was done from an area measuring $250 \mathrm{~m}^{2}$. Harvested leaves were then spread on open floors and dried at room temperature until constant weight. Dried leaves were thereafter ground to pass through a $1 \mathrm{~mm}$ sieve to produce $L$. javanica leaf meal, which was used to formulate an experimental diet.

The study consisted of three experimental diets, which were formulated by supplementing a commercial grower diet purchased from Opti feeds (PTY) LTD (Lichtenburg, North-West province) with $L$. javanica leaf meal. The 3 experimental diets were formulated using Format ${ }^{\Theta}$ as follows: (1) a negative control made up of the commercial grower diet without prophylactic antibiotics (coxistac and olaquindox), abbreviated as NegCon: (2) a positive control made up of the commercial grower diet with the antibiotics coxistac and olaquindox (PosCon): (3) commercial broiler diet without the prophylactic antibiotics but supplemented with $25 \mathrm{~g} / \mathrm{kg} \mathrm{L}$. javanica (Ljav25) (Table 1).

The L. javanica and formulated experimental diets (NegCon, PosCon and Ljav25) were analysed using the methods of AOAC International (AOAC, 2005) for Laboratory dry matter (DM; AOAC method no. 930.15), organic matter (OM; AOAC method no. 924.05). Total nitrogen was determined by the standard macro-Kjeldahl method (N; AOAC method no. 984.13) and was converted to $\mathrm{CP}$ by multiplying with the factor 6.25. Neutral detergent fibre (NDF) and acid detergent fibre (ADF) were determined using the ANKOM $^{2000}$ Fibre analyser (ANKOM Technology, New York) according to van Soest et al. (1991). Mineral matter was analysed following Agri Laboratory Association of Southern Africa guidelines (AgriLasa, 1998). 
Table 1 Gross composition of experimental diets $(\mathrm{g} / \mathrm{kg})$ offered to Japanese quails

\begin{tabular}{lccc}
\hline & \multicolumn{3}{c}{ Experimental diets $^{\mathbf{1}}$} \\
\cline { 2 - 4 } & NegCon & PosCon & Ljav25 \\
\hline Lippia javanica & 0 & 0 & 25 \\
Yellow Maize-fine & 699.0 & 699.0 & 686.9 \\
Prime-gluten 60 & 18.0 & 18.0 & 13.0 \\
Full-fat soya meal & 51.0 & 51.0 & 71.67 \\
Soybean meal & 197.0 & 197.0 & 168.0 \\
Limestone powder - fine & 14.5 & 14.5 & 14.18 \\
Mono calcium phosphate & 7.2 & 7.2 & 7.01 \\
Salt - Fine & 3.2 & 3.2 & 3.25 \\
Sodium bicarbonate & 1.7 & 1.7 & 1.65 \\
Choline powder & 0.75 & 0.75 & 0.75 \\
Lysine & 2.79 & 2.79 & 2.79 \\
L-Threonine & 0.41 & 0.41 & 0.40 \\
Methionine & 1.87 & 1.87 & 1.83 \\
Phytase & 1.67 & 1.67 & 1.67 \\
Coxistac & - & 0.5 & - \\
Olaquindox & - & 0.4 & -
\end{tabular}

${ }^{1}$ Experimental diets: NegCon = commercial grower diet without antibiotics; PosCon = commercial grower diet with antibiotics, coxistac and olaquindox; Ljav25 = commercial grower diet without antibiotics but supplemented with $25 \mathrm{~g} / \mathrm{kg}$ L. javanica

The L. javanica and formulated experimental diets (NegCon, PosCon and Ljav25) were analysed using the methods of AOAC International (AOAC, 2005) for Laboratory dry matter (DM; AOAC method no. 930.15), organic matter (OM; AOAC method no. 924.05). Total nitrogen was determined by the standard macro-Kjeldahl method (N; AOAC method no. 984.13) and was converted to CP by multiplying with the factor 6.25. Neutral detergent fibre (NDF) and acid detergent fibre (ADF) were determined using the ANKOM $^{2000}$ Fibre analyser (ANKOM Technology, New York) according to van Soest et al. (1991). Mineral matter was analysed following Agri Laboratory Association of Southern Africa guidelines (AgriLasa, 1998).

The experiment was reviewed and approved by the Animal Research Ethics Committee, Mafikeng Campus (AREC-MC) (NWU-00521-16-A9). One hundred and five, one-week old male Japanese quails were acquired from A \& J Services Farm, Palmietfontein, South Africa. The quails were reared using a starter mash (Optifeeds (PTY) LTD, Lichtenburg, North-West province) and had access to fresh water until 4 weeks of age. At 4 weeks of age, the quails were randomly allocated to 15 pens, with each pen holding 7 quails. The 3 experimental diets were randomly allocated to the pens and the quails were reared until they were 9 weeks old. The quails were allowed to adapt to the pens and diets for a week before the start of the feeding trial. The experimental unit was the pen holding 7 males each, which was replicated 5 times per dietary treatment.

Dietary treatments and water were provided ad libitum and average daily feed intake per bird was measured from week 5 to week 9 of age by subtracting the weight of the feed refusals from that of the feed offered per day, and dividing the difference by the total number of quails in the pen. Average weekly feed intake (AWFI) was calculated as the difference between the feed offered and the refusals. Quails were weighed at the beginning of the experiment, which was the first day of week 5 . Thereafter, average liveweight was measured weekly by weighing all the quails in each pen and dividing the weight by the number of birds in each pen. Average weekly weight gain (AWG) was calculated as follows:

Where: $\mathrm{t}_{0}=$ initial time;

$$
A W G\left(t_{\mathrm{o}}, T\right)=\frac{W(T)-W\left(t_{\mathrm{o}}\right)}{T-t_{\mathrm{o}}}
$$

$\mathrm{T}=$ final time; 
$W(T)=$ final body weight $(\mathrm{g})$, and

$\mathrm{W}\left(\mathrm{t}_{0}\right)=$ initial body weight $(\mathrm{g})$.

The live-weights were used to calculate weight gain. Weekly and overall feed conversion efficiency was calculated as weight gained divided by feed consumed.

At 9 weeks of age, all male Japanese quails were deprived feed for a period of 13 hours to ensure the emptiness of the crop as guided by Ari et al. (2013). All quails were taken to Rooigrond chicken abattoir (North-West province, South Africa) for slaughter. At the abattoir, all the quails were live-hanged and jammed onto a movable metal rack that holds them upside down by their feet on the rail and thereafter stunned. Quails were then slaughtered by cutting the jugular vein with a sharp knife and they were left hanging until bleeding stopped. Concurrently, about $4 \mathrm{~mL}$ of blood was collected using syringes immediately from 2 quails randomly selected from each pen into two sets of sterilised bottles (purple-top tubes with anti-coagulant for haematology and red-top tubes without anticoagulant for serum biochemical analysis). Haematological parameters (erythrocytes, haemoglobin, haematocrit, mean corpuscular volume (MCV), and mean corpuscular haemoglobin $(\mathrm{MCH})$ ) were determined using an automated IDEXX LaserCyte Haematology (IDEXX Laboratories, Inc.). Mean corpuscular haemoglobin concentration (MCHC) was calculated as the ratio between the mean corpuscular haemoglobin $(\mathrm{MCH})$ and the mean corpuscular volume (MCV). Albumin, alkaline phosphate, alanine transaminase, amylase, blood calcium, serum cholesterol, creatinine, globulin, blood glucose, lipase, blood phosphorus, total bilirubin, total protein and urea were analysed using an automated IDEXX Vet Test Chemistry Analyser (IDEXX Laboratories, Inc.).

Upon completion of bleeding the quails were put in a de-feathering machine. Afterwards, carcasses were immediately taken to the Animal Science laboratory for carcass measurements and meat quality parameters. Weights of the livers, clean gizzard, hearts, and length of small intestines were determined. Hot carcass weight (HCW) was measured before the carcasses were chilled for 24 hours to acquire the cold carcass weight (CCW). The dressing out percentage was determined as the proportion of HCW on slaughter weight. Initial meat $\mathrm{pH}$ was recorded immediately after slaughter whereas ultimate meat $\mathrm{pH}$ was measured 24 hours post slaughter on the breast muscle (central area of the breast) using a Corning Model $4 \mathrm{pH}$ temperature meter (Corning Glass Works, Medfield, MA) equipped with an Ingold spear-type electrode (Ingold Messtechnik AG, Udorf, Switzerland). Colour of the meat $\left(L^{*}=\right.$ Lightness, $a^{*}=$ Redness and $b^{*}=$ Yellowness) was determined immediately after slaughter and also 24 hours after slaughter, using a Minolta colour-guide (BYK-Gardener GmbH, Geretsried, Germany), with a $20 \mathrm{~mm}$ diameter measurement area and illuminant D65-day light, $10^{\circ}$ observation angle. The colour meter was calibrated using the green standard before measurements. Colour recording was done on the surface of the thigh muscle, which was allowed to bloom for 1 hour on a polystyrene tray at $4{ }^{\circ} \mathrm{C}$. Hue angle was calculated as $\tan ^{-1}(b * / a *)$, and Chroma was calculated as the square root of $a^{\star^{2}}+b^{\star^{2}}$ as guided by Priolo et al. (2002).

After weighing, breast samples were placed in an oven set at $130{ }^{\circ} \mathrm{C}$ for $20 \mathrm{~min}$ for determination of cooking loss. The following formula was employed:

$$
\text { Cooking losses }(\%)=\frac{\text { Initial weight }(g)-\text { Final weight }(g)}{\text { Initial weight }(g)} \times 100
$$

After determination of cooking loss, breast samples were sheared perpendicular to the fibre direction using a Meullenet-Owens razor shear blade mounted on an Universal Instron apparatus (cross head speed = $200 \mathrm{~mm} /$ minute, one shear in the centre of each core). The reported value represented the average positive peak force measurements of each sample.

All reported parameters were tested for normality using the NORMAL option in the Proc Univariate statement before being subjected to analysis of variance. Weekly feed intake, weight gain and feed conversion efficiency data were analysed using the repeated measures procedure of SAS (2010). The following statistical linear model was employed:

$$
Y_{i j k}=\mu+D_{i}+W_{j}+(D \times W)_{i j}+E_{i j k}
$$

Where: $Y_{i j k}=$ dependant variable,

$\mu=$ population mean,

$D_{i}=$ effect of diets,

$W_{j=}$ effect of week, $(\mathrm{D} \times \mathrm{W})_{i j}=$ effect of interaction between diets and week,

$E_{i k}=$ random error associated with observation $i k$, assumed to be normally and independently distributed. 
The effect of experimental diets on overall feed intake, overall weight gain, overall feed conversion efficiency, blood parameters, carcass characteristics, and meat quality data were analysed using the general linear model procedures of SAS (2010). The linear statistical model employed was as follows:

$$
Y_{i k}=\mu+D_{i}+E_{i k}
$$

Where: $Y_{i k}=$ dependant variable,

$\mu=$ population mean,

$D_{i}=$ effect of diets, and

$E_{i k}=$ random error associated with observation $i k$, assumed to be normally and independently distributed.

For all statistical tests, significance was declared at $P<0.05$. Least squares means were compared using the probability of difference (pdiff) option in the Ismeans statement of SAS.

\section{Results}

Table 2 indicates that adding Lippia javanica to the commercial grower diet increased its fibre content. Repeated measures analysis showed no significant $(P>0.05)$ week $\times$ diet interaction effect on feed intake, weight gain and feed conversion efficiency (FCE).

Table 2 Chemical composition of Lippia javanica and experimental diets (g/kg, unless stated otherwise)

\begin{tabular}{lcccc}
\hline & & \multicolumn{3}{c}{ Experimental diets } \\
\cline { 3 - 5 } & Lippia Javanica & NegCon & PosCon & Ljav25 \\
\hline Dry matter & & & & \\
Organic matter & 938.8 & 923.1 & 923.9 & 919.4 \\
Metabolisable energy (MJ/kg) & 829.3 & 874.7 & 875.6 & 871.0 \\
Crude protein & - & 117.9 & 117.9 & 121.0 \\
Crude fat & 158.1 & 189.4 & 189.4 & 179.9 \\
Neutral detergent fibre & 40.3 & 62.4 & 62.4 & 48.3 \\
Acid detergent fibre & 409.6 & 230.8 & 230.0 & 253.4 \\
Calcium & 301.6 & 52.4 & 40.2 & 59.8 \\
Phosphorus & 8.5 & 8.5 & 8.5 & 8.5 \\
Sodium & 1.59 & 5.6 & 5.6 & 5.1 \\
Potassium & 1.58 & 1.8 & 1.8 & 1.8 \\
& 30.6 & 7.3 & 7.3 & 7.6 \\
\hline
\end{tabular}

The effect of experimental diets on AWFI, AWG, and FCE is shown in Table 3. For the entire duration of the study, diet had no significant influence on AWFI, AWG, and FCE.

Similarly, there was no dietary effect $(P>0.05)$ on overall feed intake, overall weight gain and FCE for the entire duration of the study (Table 4).

For haematological parameters, Table 5 indicates that diet had no influence $(P>0.05)$ on erythrocytes, haemoglobin, haematocrit, mean corpuscular volume (MCV), mean corpuscular haemoglobin (MCH) and mean corpuscular haemoglobin concentration $(\mathrm{MCHC})$ of Japanese quails. 
Table 3 The effect of experimental diets on weekly feed intake, weight gain and FCE of Japanese quails

\begin{tabular}{|c|c|c|c|c|c|}
\hline & & \multicolumn{3}{|c|}{ Experimental diets } & \multirow[b]{2}{*}{${ }^{1}$ SEM } \\
\hline & & NegCon & PosCon & Ljav25 & \\
\hline \multirow{5}{*}{ Intake (g) } & Week 6 & 180.96 & 166.64 & 174.04 & 9.54 \\
\hline & Week 7 & 152.68 & 136.4 & 141.2 & 7.77 \\
\hline & Week 8 & 147.4 & 129.34 & 125.52 & 10.70 \\
\hline & Week 9 & 133.22 & 128.3 & 130.58 & 8.911 \\
\hline & Week 6 & 15.32 & 22.22 & 27.08 & 5.464 \\
\hline \multirow{2}{*}{ Gain (g) } & Week 7 & 3.55 & 2.35 & 3.83 & 2.006 \\
\hline & Week 8 & 3.14 & 2.38 & 2.64 & 0.764 \\
\hline \multirow{5}{*}{${ }^{2} \mathrm{FCE}$ (g gain/g feed consumed) } & Week 9 & 2.03 & 3.75 & 2.3 & 1.120 \\
\hline & Week 6 & 0.084 & 0.132 & 0.162 & 0.033 \\
\hline & Week 7 & 0.022 & 0.015 & 0.027 & 0.014 \\
\hline & Week 8 & 0.022 & 0.019 & 0.02 & 0.006 \\
\hline & Week 9 & 0.015 & 0.028 & 0.012 & 0.009 \\
\hline
\end{tabular}

$\mathrm{SEM}^{1}=$ standard error of the mean

$\mathrm{FCE}^{2}$ = feed conversion efficiency

Table 4 The effect of experimental diets on overall feed intake, overall weekly gain and FCE of 9-week old Japanese quails

\begin{tabular}{lcccc}
\hline & \multicolumn{3}{c}{ Experimental diets } & \multirow{2}{*}{ 1SEM } \\
\cline { 2 - 4 } & NegCon & PosCon & Ljav25 & \\
\hline Overall Intake $(\mathrm{g})$ & 614.2 & 560.7 & 571.3 & 29.893 \\
Overall Gain $(\mathrm{g})$ & 22.9 & 29.46 & 34.66 & 5.285 \\
Overall FCE (g gain/ g feed consumed) & 0.14 & 0.19 & 0.22 & 0.03 \\
TSEM = standard error of the mean & & &
\end{tabular}

Table 5 The effect of experimental diets on haematological parameters of 9-week old Japanese quails

\begin{tabular}{lcccc}
\hline \multirow{2}{*}{${ }^{1}$ Haematological parameters } & \multicolumn{3}{c}{ Experimental diets } \\
\cline { 2 - 4 } & NegCon & PosCon & Ljav25 & 2SEM \\
\hline Erythrocytes $\left(\times 10^{12} / \mathrm{L}\right)$ & 3.74 & 3.67 & 3.67 & 0.063 \\
Haemoglobin $(\mathrm{g} / \mathrm{dL})$ & 15.57 & 14.95 & 15.28 & 0.307 \\
Haematocrit $(\mathrm{L} / \mathrm{L})$ & 0.60 & 0.59 & 0.56 & 0.014 \\
$\mathrm{MCV}(\mathrm{fL})$ & 161.6 & 151.8 & 150.4 & 5.433 \\
$\mathrm{MCH}(\mathrm{pg})$ & 42.1 & 40.83 & 41.71 & 1.087 \\
$\mathrm{MCHC}(\mathrm{g} / \mathrm{dL})$ & 26.65 & 27.05 & 27.23 & 0.953
\end{tabular}

\footnotetext{
${ }^{1}$ Haematological parameters: $\mathrm{MCV}=$ mean corpuscular volume; $\mathrm{MCH}=$ mean corpuscular haemoglobin; $\mathrm{MCHC}=$ mean corpuscular haemoglobin concentration.

${ }^{2} \mathrm{SEM}=$ standard error of the mean
} 
The effects of diets on serum biochemical constituents are shown in Table 6. Experimental diets had no effect $(P>0.05)$ on all serum biochemical parameters, except for alanine transaminase (ALT). Quails offered Ljav25 had higher ALT content $(56.83 \mu / L)$ than those offered PosCon $(18.0 \mu / L)$. However, NegCon and PosCon diets were shown to promote similar $(P>0.05)$ ALT content while quails offered NegCon also had similar ALT content as those offered Ljav25 $(P>0.05)$.

Table 6 Serum biochemical values (mean \pm SEM) of 9-week old Japanese quails by diets

\begin{tabular}{lccc}
\hline & & Experimental diets & Ljav25 \\
\hline & NegCon & PosCon & $56.83^{\mathrm{b}} \pm 10.26$ \\
\cline { 2 - 4 } Alanine transaminase $(\mathrm{u} / \mathrm{L})$ & & $18.0^{\mathrm{a}} \pm 8.89$ & $30.67 \pm 5.726$ \\
Albumin $(\mathrm{g} / \mathrm{L})$ & $39.2^{\mathrm{ab}} \pm 11.24$ & $16.88 \pm 5.726$ & $55.80 \pm 16.542$ \\
Alkaline phosphate $(\mathrm{u} / \mathrm{L})$ & $19.6 \pm 5.726$ & $61.75 \pm 16.542$ & $333.8 \pm 85.296$ \\
Amylase (u/L) & $39.6 \pm 16.542$ & $380.0 \pm 85.296$ & $1.95 \pm 0.13$ \\
Calcium (mmol/L) & $471.8 \pm 85.296$ & $2.15 \pm 0.13$ & $5.50 \pm 0.609$ \\
Cholesterol (mmol/L) & $1.97 \pm 0.13$ & $5.81 \pm 0.609$ & $27.33 \pm 4.981$ \\
Creatinine (umol/L) & $6.06 \pm 0.609$ & $16.75 \pm 4.981$ & $25.2 \pm 3.601$ \\
Globulin (g/L) & $17.0 \pm 4.981$ & $22.5 \pm 3.601$ & $3.69 \pm 1.586$ \\
Glucose (mmol/L) & $26.0 \pm 3.601$ & $3.89 \pm 1.586$ & $281.3 \pm 37.924$ \\
Lipase (u/L) & $2.52 \pm 1.586$ & $167.0 \pm 37.924$ & $5.18 \pm 0.165$ \\
Phosphorus (mmol/L) & $226.6 \pm 37.924$ & $5.15 \pm 0.165$ & $146.5 \pm 52.05$ \\
Total bilirubin (umol/L) & $4.69 \pm 0.165$ & $24.5 \pm 52.05$ & $61.67 \pm 10.525$ \\
Total protein (g/L) & $44.60 \pm 52.05$ & $39.38 \pm 10.525$ & $3.05 \pm 0.973$ \\
Urea (mmol/L) & $45.60 \pm 10.525$ & $1.18 \pm 0.973$ & \\
\hline
\end{tabular}

${ }^{\text {a.b }}$ Row means with different superscripts differ significantly at $P<0.05$

Table 7 indicates the effect of experimental diets on carcass characteristics and internal organs of Japanese quails. With the exception of gizzard weights, diets had no effect on carcass characteristics and internal organs. Supplementation with $L$. javanica had the same $(P>0.05)$ effect on gizzard weights of Japanese quails as PosCon. Quails offered diet NegCon had higher gizzard weight $(3.47 \mathrm{~g})$ when compared to those offered PosCon and Ljav25, which did not differ $(P>0.05)$.

Table 7 The effect of experimental diets on carcass characteristics and internal organs of Japanese quails

\begin{tabular}{lcccc}
\hline & \multicolumn{3}{c}{ Experimental diets } & \multirow{2}{*}{ 1SEM } \\
\cline { 2 - 4 } & NegCon & PosCon & Ljav25 & \\
\hline${ }^{2} \mathrm{HCW}(\mathrm{g})$ & 122.3 & 112.0 & 109.5 & 5.936 \\
${ }^{3} \mathrm{CCW}(\mathrm{g})$ & 108.3 & 111.9 & 108.3 & 3.739 \\
Dressing out \% & 67.82 & 65.43 & 61.45 & 2.33 \\
Gizzards (g) & $3.47^{\mathrm{b}}$ & $2.34^{\mathrm{a}}$ & $2.48^{\mathrm{a}}$ & 0.216 \\
Hearts (g) & 1.37 & 1.23 & 1.42 & 0.081 \\
Livers (g) & 1.2 & 1.69 & 2.28 & 0.19 \\
Small intestines (cm) & 15.08 & 15.11 & 16.01 & 0.436 \\
\hline
\end{tabular}

${ }^{1} \mathrm{SEM}=$ standard error of the mean

${ }^{2} \mathrm{HCW}=$ hot carcass weight

${ }^{3} \mathrm{CCW}=$ cold carcass weight

a.b Row means with different superscripts differ significantly at $P<0.05$ 
The effect of diets on meat quality parameters of Japanese quails is presented in Table 8 . The experimental diets caused no significant variation in meat quality parameters, except for meat lightness $\left(L^{*}\right)$, immediately after slaughter. Quails offered NegCon had lower $L^{*}(46.2)$ than those offered PosCon and Ljav25, which did not differ $(P>0.05)$. Table 8 shows the effect of diets on meat quality parameters $24 \mathrm{~h}$ post slaughter of Japanese quails. Experimental diets had no influence on meat quality parameters, except on meat yellowness $\left(b^{*}\right)$. Quails offered Ljav25 had higher meat yellowness (6.39) than those offered NegCon and PosCon, which did not differ $(P>0.05)$.

The effect of experimental diets on cooking loss and peak positive force are shown in Figure 1. Diets had no influence on PPF values but affected cooking losses of Japanese quail meat. NegCon diet had the lower cooking losses $(16.51 \%)$ when compared to PosCon and Ljav25, which did not differ $(P>0.05)$.

Table 8 The effect of experimental diets on meat quality parameters (mean \pm SEM) immediately after slaughter of 9-week old Japanese quails

\begin{tabular}{llccc}
\hline & Meat traits & \multicolumn{3}{c}{ Experimental diets } \\
\cline { 3 - 4 } & & NegCon & PosCon & Ljav25 \\
\cline { 2 - 4 } At slaughter & Meat Ph & $7.71 \pm 0.059$ & $7.80 \pm 0.059$ & $7.81 \pm 0.059$ \\
& Lightness $\left(L^{*}\right)$ & $46.20^{\mathrm{a}^{*}} \pm 0.648$ & $48.50^{\mathrm{b}} \pm 0.615$ & $48.11^{\mathrm{b}} \pm 0.648$ \\
& Redness $\left(a^{*}\right)$ & $1.70 \pm 0.612$ & $1.64 \pm 0.612$ & $2.31 \pm 0.612$ \\
& Yellowness $\left(b^{*}\right)$ & $8.66 \pm 0.979$ & $7.23 \pm 0.979$ & $5.20 \pm 0.979$ \\
& Chroma & $8.85 \pm 0.932$ & $7.29 \pm 0.932$ & $6.20 \pm 0.932$ \\
& Hue Angle & $1.38 \pm 0.969$ & $2.88 \pm 0.969$ & $1.08 \pm 0.969$ \\
& Meat pH & $6.99 \pm 2.343$ & $6.94 \pm 2.343$ & $6.80 \pm 2.343$ \\
& Lightness $\left(L^{*}\right)$ & $45.04 \pm 3.000$ & $44.46 \pm 3.000$ & $49.42 \pm 3.000$ \\
& Redness $\left(a^{*}\right)$ & $3.29 \pm 0.540$ & $3.42 \pm 0.540$ & $2.98 \pm 0.540$ \\
& Yellowness $\left(b^{*}\right)$ & $3.11^{\mathrm{a}^{*}} \pm 0.821$ & $3.76^{\mathrm{a}} \pm 0.779$ & $6.39^{\mathrm{b}} \pm 0.821$ \\
& Chroma & $4.73 \pm 0.850$ & $5.36 \pm 0.850$ & $7.26 \pm 0.850$ \\
& Hue Angle & $1.52 \pm 0.621$ & $1.60 \pm 0.621$ & $1.08 \pm 0.621$ \\
& & & \\
\hline
\end{tabular}

${ }^{a . b}$ Row means with different superscripts differ significantly at $P<0.05$

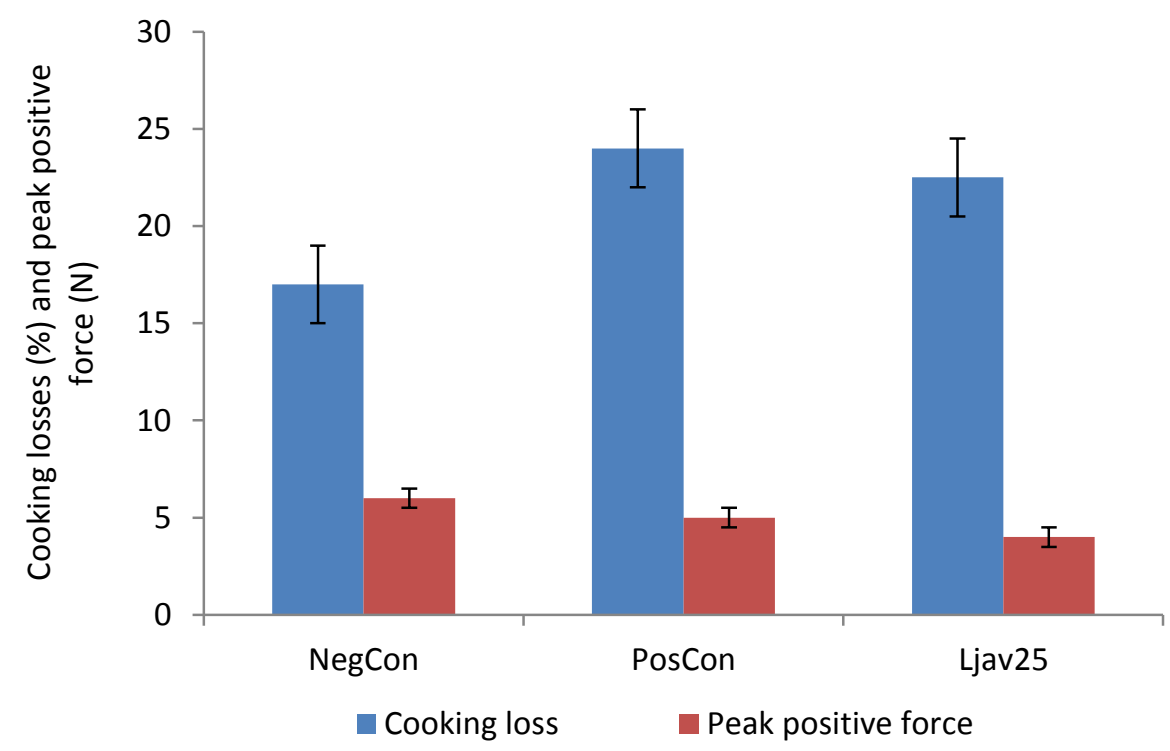

Figure 1 Cooking losses (\%) and peak positive force $(\mathrm{N})$ of Japanese quails as affected by diet 


\section{Discussion}

The current study was conducted to evaluate $L$. javanica leaf meal as a natural antibiotic growth promoter in place of commercial antibiotics in Japanese quails' diets. Repeated measures analysis showed no significant week $x$ diet interaction effect on average weekly feed intake (AWFI), average weekly weight gain (AWG) and feed conversion efficiency (FCE), suggesting that the ability of the quails to utilise the different experimental diets was not influenced by age. The inclusion of $L$. javanica leaf meal promoted similar feed intake as the control diets, suggesting that although the NDF and ADF content of $L$. javanicabased diet was higher than the negative and positive control diets, this did not negatively influence feed intake as would be expected at higher fibre inclusion rates. However, considering that the inclusion level of Lippia was only $2.5 \%$, it is unlikely that the fibre content would have induced any influence on feed intake. As reported by Sarıçiçek et al. (2005), higher fibre levels may reduce voluntary feed intake in simple nonruminants whose ability to utilise fibrous diets is limited. In contrast with the findings of this study, Mpofu et al. (2016) found that diluting a commercial grower diet with $L$. javanica reduced feed intake in broilers. This discordance might be due to differences in the genetic potential of the bird species with quails showing greater capacity to utilise fibre.

Antibiotic growth promoters are well-known to improve nutrient utilization by the host, modulate the immune system, stimulate beneficial bacteria, and direct reduction of pathogens (Kocher \& Choct, 2008). In terms of overall feed intake, overall weight gain and FCE, L. javanica promoted similar performance as the control diet containing conventional AGPs as well as the negative control. The similarity of the Lippia-based diet to the negative control diet (without antibiotics) was not expected, but could be due to the fact that the experiment was started when the quails had reached 5 weeks of age, which was enough time for them to have developed strong immunity as they are known to grow and develop rapidly. Haematological profile in animals is an important indicator of physiological or pathophysiological status of the body (Khan \& Zafar, 2005). Dietary treatments had no significant impact on haematological parameters of Japanese quails, which fell within the normal range for quails, suggesting that adding $L$. javanica to quail diets did not negatively influence the physiological status of quails. Similarly, inclusion of Lippia in quails' diet had no significant effect on all serum biochemical parameters, except for alanine transaminase (ALT). The Lippia-based diet promoted ALT levels similar to those in negative control quails while the positive control quails had lower levels. As reported by Evans (2009), levels of ALT may be increased in cases of hepatitis, congestive heart failure, and liver or biliary duct damage. It is not clear what caused the elevation of ALT in quails offered $L$. javanica-based diet and those offered the negative control diet even though liver weights tended $(P>0.05)$ to be larger in Lippia supplemented quails. The aminotransferases, AST and ALT, are normally contained within liver cells and are released into the blood when liver cells are damaged. Dietary treatments had no negative impact on liver weights, an indication that $L$. javanica does not contain large quantities of antinutritional compounds that require detoxification. The liver is a source of many proteins, and liver function is often evaluated by measuring total serum protein, albumin, and globulin levels (Evans, 2009). Increased plasma amylase and bilirubin is also indicative of tissue damage in liver (Evans, 2009) while creatinine is a more reliable indicator of renal function, which were all not significant in this study. Braun et al. (2010) also added that the aminotransferase is elevated in serum under conditions of significant cellular necrosis and is used as a measure of liver function. The fact that Lippia-based diet promoted similar levels of all these biochemical parameters as the positive control is further testimony that $L$. javanica leaf meal is safe to use as a feed additive in Japanese quail diets. Diets had no impact on serum urea concentrations in our study, indicating functional kidneys.

With the exception of gizzard weights, diets did not influence carcass characteristics and internal organs. Supplementation with $L$. javanica had the same $(P>0.05)$ effect on gizzard weights of Japanese quails as PosCon. Although, diet Ljav25 was expected to promote larger gizzard weights, due to increased fibre levels (Table 2), as a mechanism for the quail to cope with higher levels of harder-to-digest fibre components. This result contradicts the findings by Mpofu et al. (2016), who observed higher proventriculus and gizzard weights as well as longer small intestines in broilers fed $L$. javanica at the rate of $12 \mathrm{~g} / \mathrm{kg}$. The differences could be because the inclusion of Lippia was lower in the current study. Quails offered the negative control diet had lower $L^{*}$ value (46.2) than those offered the positive control and Lippia-based diets, which was against our expectations and the findings of Mapiye et al. (2011) that phytogenic plants may promote lighter meat colour. Quails offered the Lippia-based diet had higher meat yellowness (6.39) than those offered the two control diets, this can be attributed to the presence of pigments, including carotene in the green leaves of Lippia, which suggests that feeding Lippia instead of AGPs can increase meat flavour and increase the amount of vitamin A in the meat. Diets had no significant influence in PPF values of male Japanese quails, suggesting that substituting AGPs with $L$. javanica did not negatively affect meat texture. 


\section{Conclusions}

The inclusion of $L$. javanica in quail diets at $25 \mathrm{~g} / \mathrm{kg}$ feed promoted similar growth performance, health status, and carcass and meat quality traits as the commercial grower diet containing antibiotics. Lippia javanica leaf meal, therefore, has the potential to be used as an alternative to antibiotic growth promoters in Japanese quails.

\section{Acknowledgements}

The financial assistance of the Health and Welfare Sector Education and Training Authority (HWSETA) is hereby acknowledged. We are also grateful to Mafikeng Game Reserve for granting us permission to harvest the Lippia javanica.

\section{Conflict of Interest Declaration}

The authors declare that they have no conflict of interests

\section{Authors' Contributions}

CMM and VM designed the study. CCM, TBM and RVN conducted the feeding trial and data collection. CCM and VM statistically analysed the data and wrote the paper.

\section{References}

Aarestrup, F.M., 2003. Effects of termination of AGP use on antimicrobial resistance in food animals. World Health Organization, Geneva, Switzerland. pp. 6-11.

Abena, A.A., Diatewa, M., Gakosso, G., Geassor, M., Hondi-Assah, T.H. \& Ouamba, J.M., 2003. Analgesic, antipyretic and anti-inflammatory effects of essential oils of Lippia multiflora. Fitoterapia. 74, 231-6.

AgriLASA, 1998. Feed and Plant Analysis Methods. Agri Laboratory Association of Southern Africa, Pretoria, South Africa.

AOAC, 2005. Official Methods of Analysis of AOAC International (17th ed.). Association of the Official Analytical Chemists. Gaithersburg. MD. USA

Ari, M.M., Ayanwale, B.A. \& Ogah, D.M., 2013. Effects of alkali treatment of soyabean on carcass traits, intestinal morphology and cooking yield of broilers. Trakia J. Sci. 2, 189-196.

Ayaşan, T., 2013. Effects of dietary Yucca schidigera on hatchability of Japanese Quails. Indian J. Anim. Sci. 83, 641 644.

Ayaşan, T., Yurtseven, S., Kutlu, H.R. \& Baylan, M., 2011. Effects of boric acid supplementation on egg production and quality of Japanese Quails (Coturnix coturnix Japonica). Indian J. Anim. Sci. 81, 534-36.

Braun, J.P., Trumela, C. \& Bézille, P., 2010. Clinical biochemistry in sheep: A selected review. Small Rumin Res. 92, 1018.

Cong, W., Hong-Liang, J., Xiao-Xuan, Z., Qing-Feng, M., Jian-Gang, M., Ai-Dong, Q. \& Xing-Quan, Z., 2017. First genetic characterization of Toxoplasma gondii infection in common quails (Coturnix coturnix) intended for human consumption in China. Infect. Genet. Evolut. 49, 14-16.

Dibner, J.J. \& Richards, J.D., 2005. Antibiotic growth promoters in agriculture: History and mode of action. Poult. Sci. 84, 634-643.

Evans, G.O., 2009. Animal Clinical Chemistry. CRC Press, Boca Raton FL.

Khan, A.T. \& Zafar, F., 2005. Haematological study in response of varying doses of oestrogen in broiler chicken. Int. J. Poult. Sci. 4, 748-751.

Khosravi, H., Mehri, M., Bagherzadeh-Kasmani, F. \& Asghari-Moghadam, M., 2016. Methionine requirement of growing Japanese quails. Anim. Feed Sci. Technol. 212, 122-128.

Kocher, A. \& Choct, M., 2008. Improving broiler chicken performance. RIRDC. Pp. 1-82.

Landy, N., Ghalamkari, G. \& Toghyani, M., 2011. Performance, carcass characteristics, and immunity in broiler chickens fed dietary neem (Azadirachta indica) as alternative for an antibiotic growth promoter. Livest. Sci., 142, 305-309.

Manezhe, N.J., Potgieter, N. \& Ree, T., 2004. Composition and anti-microbial activities of volatile components of Lippia javanica. Phytochemistry. 16, 2333-6.

Mapiye, C., Chimonyo, M., Dzama, K., Hugo, A., Strydom, P.E. \& Muchenje V., 2011. Fatty acid composition of beef from Nguni steers supplemented with Acacia karroo leaf-meal. J. Food Comp. Anal. 24, 523-528.

Mpofu, D.A., Marume, U, Mlambo, V. \& Hugo, A., 2016. The effects of Lippia javanica dietary inclusion on growth performance, carcass characteristics and fatty acid profiles of broiler chickens. Anim. Nutr. 2, 160-167.

Muyima, N.Y.O., Nziweni, S. \& Mabinya, L.V., 2004. Antimicrobial and antioxidative activities of Tagetes minuta, Lippia javanica and Foeniculum vulgare essential oils from the Eastern Cape Province of South Africa. J. Essent. Oil bear. PI. 7, 68-78.

Phillips, I., Casewell, M., Cox, T., De Groot, B., Friis, R., Jones, C., Nightingale, R., Preston, R. \& Waddell, J., 2004. Does the use of antibiotics in food animals pose a risk to human health? A critical review of published data. J. Antimicrob. Chemoth. 53, 28-52.

Priolo, A., Micol, D., Agabriel, J., Prache, S. \& Dransfield, E., 2002. Effect of grass or concentrate feeding systems on lamb carcass and meat quality. Meat Sci. 62, 179-185. 
Qwele, K., Muchenje, V., Oyedemi, S.O., Moyo, B. \& Masika, P.J., 2013. Chemical composition, fatty acid contents and antioxidant potential of meat from goats supplemented with Moringa (Moringa oleifera) leaves, sunflower cake and grass hay. Meat Sci. 93, 455-62.

Sarıçiçek, B.Z., Kılıç, Ü. \& Garipoğlu, A.V., 2005. Replacing soybean meal (SBM) by canola meal (CM): the effects of multi-enzyme and phytase supplementation on the performance of growing and laying quails. Asian-Aust. J. Anim. Sci. 18, 1457 - 1463.

SAS, 2010. Users Guide: Statistics. Version 9.3. SAS Institute, Cary, NC, USA.

Sreelatha, S. \& Padma, P.R., 2011. Antioxidant activity and total phenolic content of Moringa oleifera leaves in two stages of maturity. J. Plant Food Hum. Nutr. 64, 303-311.

Toghyani, M., Toghyani, M., Gheisari, A.A., Ghalamkari, G.H. \& Mohammadrezaei, M., 2010. Growth performance, serum biochemistry, and blood hematology of broiler chicks fed different levels of black seed (Nigella sativa) and peppermint (Mentha piperita). Livest. Sci. 129, 173-178.

Van Soest, P.J., Robertson, J.B. \& Lewis, B.A., 1991. Methods for dietary fiber, neutral detergent fiber, and non-starch polysaccharides in relation to animal nutrition. J. Dairy Sci. 74, 3583-3597.

Viljoen, A.M., Subramoney, S., van Vuuren, S.F., Baer, K.H.C. \& Demirci, B., 2005. The composition, geographical variation and antimicrobial activity of Lippia javanica (Verbenaceae) leaf essential oils. J. Ethnopharmacol. 96, $271-277$

Wallace, R.J., Oleszek, W., Franz, C., Hahn, I., Baser, K.H.C., Mathe A. \& Teichmann, K., 2010. Dietary plant bioactives for poultry health and productivity. Br. Poult. Sci. 51, 461-487.

Windisch, W., Schedle, K., Plitzner, C. \& Kroismayr, A., 2008. Use of phytogenic products as feed additives for swine and poultry. J. Anim. Sci. 86, 140-148. 